\title{
ESTRUCTURA, ANÁLISIS NARRATOLÓGICO Y CONTEXTUAL DE JN 7,53-8,11
}

\author{
Structure, Narratological and Contextual Analysis of Jn 7,53-8,11
}

\author{
FACUNDO Mela, FDP ${ }^{1}$
}

\section{Resumen}

El Papa Francisco recuerda con insistencia que la misericordia es el centro del mensaje del Evangelio. Años antes, el Card. Walter Kasper advertía que la misericordia había caído en el olvido de la teología sistemática. Junto con ello, existe una nueva sensibilidad ante la problemática de la violencia de género. Esto hace que los cristianos repensemos nuestros modos de sentir y de actuar. El relato conocido como La mujer adúltera (Jn 7,53-8,11) es un ejemplo de la praxis misericordiosa de Jesús con las mujeres y con quienes no tienen voz. Es un texto rico en humanidad que presenta dos actitudes contrapuestas ante el pecado: el legalismo y la misericordia. Presenta el novedoso y revolucionario modo en el que Jesús se relaciona con la mujer en una sociedad en la que ésta no era considerada. Este trabajo ofrece un aporte al estudio de la perícopa desde la aplicación del análisis de la estructura y del método narrativo. Por otra parte, la perícopa es considerada por los especialistas como un texto lucano inserto en el cuarto Evangelio por el corte narrativo en el discurso de la Fiesta de los Tabernáculos (capítulos 7 y 8) y por sus características estilísticas y su ausencia, o posición diversa, en algunos manuscritos antiguos (principalmente anteriores al siglo III). Su actual ubicación canónica es una incógnita y llamativamente son pocas las explicaciones y ensayos que intentan dar una respuesta a esta problemática. En este estudio, el análisis de la estructura del texto presenta cómo la pregunta acerca del pecado personal, hecha por Jesús, es el corazón del enfrentamiento con los escribas y los fariseos. La aplicación del método narrativo pone de manifiesto una cantidad de características y detalles del relato que podrían ser pasados por alto por otros métodos o aproximaciones. Ambos análisis son una contribución a la investigación por los datos que arrojan. Por su parte, el análisis contextual de la perícopa da una respuesta posible y válida a la cuestión de la ubicación actual, pero a modo de first approach.

Palabras clave: Análisis narratológico; Narratología; Juan; Mujer Adúltera; Misericordia; Mujer.

1 Licenciado en Teología con especialización en Sagrada Escritura, Pontificia Universidad Católica Argentina. Representante legal y docente del Instituto Don Orione (Presidencia Roque Sáenz Peña, Chaco, Argentina). Sacerdote de la Pequeña Obra de la Divina Providencia, Obra de Don Orione.

Correo electrónico: facundofdp@yahoo.com.ar 


\section{Abstract}

Pope Francis insistently repeats that mercy is at the core of the teachings of the Gospel. Years ago, Cardinal Walter Kasper also stated that mercy had been forgotten within systematic theology. Additionally, there is a new sensitivity towards gender violence. Those ideas make Christians to reconsider our ways of feeling and acting. Bearing this in mind, the passage of the adulterous woman (Jn 7:53 - 8:11) is an example of the merciful actions of Jesus towards women and those who have no voice. It is a passage full of humanity in which two opposed attitudes towards sin are introduced: legalism and mercy. It also introduces the original and revolutionary way in which Jesus relates to women in a society that did not consider them. Thus, the article contributes to the study of the passage addressing it from the perspective of structural and narrative analysis. Scholars consider this passage as a Lucan one that is inserted into the fourth gospel due to the cut within the discourse of the Feast of Tabernacles (chapters 7 and 8) and because of its characteristic style and absence -or different position-in some manuscripts (specially, those previous to the third century). The current canonical location remains a mystery and, noteworthy, there are few researches that address such issue. In this article, the structural analysis suggests that the question framed by Jesus regarding personal sin is the key aspect of his conflict with scribes and pharisees. The use of narrative analysis makes clear some features and details of the passage that could be overlooked with other methods and approaches. Finally, the contextual analysis of the passage provides a possible answer to the issue of its current location, but just as a first approach.

Key words: Narrative Analysis; Narratology; John; Adulterous Woman; Mercy; Woman.

\section{Introducción}

En 2012, el Card. Walter Kasper advertía que la misericordia había caído en el olvido de la teología sistemática o era tratada de forma negligente por ésta (Kasper, 2014, p. 9). El Papa Francisco, por su parte, presenta la misericordia como el mensaje central del Evangelio. Junto con ello, el surgimiento de una nueva sensibilidad ante la violencia de género, muy extendida en nuestro continente, hace que los cristianos repensemos nuestros modos de sentir y de actuar.

Por ello, el relato conocido como La mujer adúltera (Jn 7,53-8,11) ofrece pistas para profundizar la praxis misericordiosa de Jesús con mujeres y con aquellos que no tienen en la presencia en la sociedad. Con este objetivo, creemos que los métodos literarios pueden ofrecer un aporte en esta búsqueda y, por ello, en este estudio se aplicará el análisis de la estructura y el método narrativo en dicho texto.

Por otra parte, la perícopa es considerada una interpolación lucana en el Evangelio de Juan por su terminología y estilo, como también por el corte narrativo que se produce en el discurso de la fiesta de los Tabernáculos. El texto no aparece en los manuscritos más antiguos, sino en los posteriores al siglo III y con distintas ubicaciones en el cuarto Evangelio ${ }^{2}$. Su posición actual plantea un interrogante a los investigadores: si se debe a un error humano (del escritor, copista o recopilador) o si posee una razón narratológica.

2 La mayoría de los manuales y comentarios sobre el Evangelio de Juan se explayan acerca de esta problemática. 
En este trabajo se presentará, primero, la estructura del texto y su análisis; luego, se aplicarán algunas instancias del método narrativo y, finalmente, se expondrá una hipótesis acerca de la ubicación de la perícopa desde la narratología.

\section{Estructura propuesta y su análisis}

La perícopa está compuesta por doce versículos: los tres primeros son introductorios $(7,53-8,2)$, mientras que los nueve restantes, en los que se da propiamente la estructura, se despliega el enfrentamiento entre Jesús y el grupo de los escribas y los fariseos (8,3-11).

\section{La estructura}

La discusión entre Jesús y los escribas y los fariseos por la mujer adúltera $(8,3-11)$ posee una forma concéntrica ${ }^{3}$, la que se expone de dos maneras:

Cuadro 1. Estructura concéntrica

\begin{tabular}{|c|c|c|}
\hline A & Llegada de los acusadores & ${ }^{3}$ Los escribas y los fariseos le llevan \\
\hline B & La mujer ante los acusadores y Jesús & una mujer sorprendida en adulterio, la ponen en medio \\
\hline $\mathrm{C}$ & La condena & $\begin{array}{l}{ }^{4} \text { y le dicen: "Maestro, esta mujer ha sido sorprendida en flagrante } \\
\text { adulterio. }\end{array}$ \\
\hline D & Consecuencia: castigo & ${ }^{5}$ Moisés nos mandó en la Ley apedrear a estas mujeres. \\
\hline $\mathbf{E}$ & La pregunta a Jesús sobre la mujer & $\begin{array}{l}\text { ¿Tú qué dices?" } 6 \text { Esto lo decían para tentarle, para tener de qué } \\
\text { acusarle. }\end{array}$ \\
\hline $\mathbf{F}$ & Jesús escribe inclinado & Pero Jesús, inclinándose, se puso a escribir con el dedo en la tierra. \\
\hline $\mathbf{X}$ & La respuesta de Jesús & $\begin{array}{l}{ }^{7} \text { Pero, como ellos insistían en preguntarle, se incorporó y les dijo: } \\
\text { "Aquel de vosotros que esté sin pecado, que le arroje la primera } \\
\text { piedra". }\end{array}$ \\
\hline F' & Jesús escribe inclinado & ${ }^{8}$ E inclinándose de nuevo, escribía en la tierra. \\
\hline$\overline{A^{\prime}}$ & Retirada de los acusadores & $\begin{array}{l}{ }^{9} \text { Ellos, al oír estas palabras, se iban retirando uno tras otro, } \\
\text { comenzando por los más viejos }\end{array}$ \\
\hline B' & La mujer ante Jesús & y se quedó solo Jesús con la mujer, quien seguía en medio. \\
\hline $\mathbf{E}^{\prime}$ & Las preguntas de Jesús a la mujer & $\begin{array}{l}{ }^{10} \text { Incorporándose Jesús le dijo: "Mujer, ¿dónde están? ¿Nadie te ha } \\
\text { condenado?" }{ }^{11} \text { Ella respondió: "Nadie, Señor." }\end{array}$ \\
\hline$C^{\prime}$ & La ausencia de condena & Jesús le dijo: "Tampoco yo te condeno. \\
\hline $\mathbf{D}^{\prime}$ & $\begin{array}{l}\text { Consecuencia: invitación a no pecar } \\
\text { más }\end{array}$ & Vete, y en adelante no peques más". \\
\hline
\end{tabular}

Fuente: elaboración propia.

3 "Una estructura con una cantidad impar de elementos se llama concéntrica, pues sus elementos forman como círculos o anillos equidistantes de un centro común. Se trata de un procedimiento que dispone palabras, frases, elementos o unidades menores en orden invertido, en el que el primero corresponde al último, el segundo al penúltimo, y así sucesivamente. El elemento medular sin correspondencia constituye el centro, del cual equidistan los elementos pares que se corresponden" (Krüger, Croatto \& Míguez, 1996, p. 265.) 
La estructura puede ser representada alternativamente del siguiente modo:

Gráfico 1. Estructura concéntrica
A Llegada de los acusadores
B La mujer ante los acusadores y Jesús
C La condena
D Consecuencia: castigo
E La pregunta a Jesús sobre la mujer

F Jesús se inclina y escribe

X Respuesta de Jesús

F' Jesús se inclina y escribe
A' Retirada de los acusadores
B’ La mujer ante Jesús
C' La ausencia de condena
D’ Consecuencia: invitación a no pecar más
E’ Las preguntas de Jesús a la mujer

Fuente: elaboración propia.

A partir de ambos esquemas, se aprecia que la discusión entre Jesús y el grupo acusador por la mujer adúltera está compuesto de cinco bloques concéntricos con 13 segmentos, de los cuales E’ rompe el orden que aparece en la primera parte.

\section{Análisis de la estructura de la discusión}

En el primer bloque (3-6a), escribas y fariseos se presentan ante Jesús (A) quien se encontraba en el templo enseñando $(8,1-2)$, éstos llevan ante él una mujer sorprendida en adulterio, quien es ubicada entre este grupo y Jesús (B). De acuerdo con la Ley de Moisés (Nm 5,11, Lv 20,10, Dt 17,5-7; 19,15-21; 22,2227), la mujer ya está condenada (C) y, por tanto, merece un castigo: ser apedreada (D). Tras presentar el caso, los escribas y los fariseos preguntan a Jesús acerca de su opinión, pero no para buscar una enseñanza sino para tenderle una trampa (E). 
El quinto bloque (9-11) se encuentra en correlato temático con el primero, pero con una variación en el orden. Los escribas y los fariseos se retiran (A') luego de los gestos y palabras de Jesús (6b-8), y lo dejan a solas con la mujer, quien permanece en el mismo lugar (B'), aunque sus acusadores han desaparecido de la escena. Se rompe el orden paralelo, Jesús antes de llevar adelante algún tipo de acción sobre la mujer, dialoga con ella y le pregunta por sus acusadores (E'). Ante la ausencia de éstos y, por tanto, de una condena (C’) deviene como consecuencia: la invitación a un cambio de vida (D’).

La similitud entre el segundo (6b) y cuarto bloques (8) es más evidente que la anterior por cuanto Jesús realiza una misma acción sin cambiar de lugar.

6b Pero, Jesús, inclinándose, se puso a escribir con el dedo en la tierra

8 E inclinándose de nuevo, escribía en la tierra

El bloque central (o tercero) no posee correlato. La respuesta ubicada en el centro de la estructura produce un cambio radical en la situación: los acusadores se retiran, Jesús cambia de interlocutor y la mujer no es condenada.

\section{Análisis narrativo}

En esta segunda sección, se estudian el relato y los diversos elementos que lo componen desde una perspectiva narratológica.

Cuadro 2. Aplicación del esquema quinario de Paul Larivaille ${ }^{4}$

\begin{tabular}{|c|c|}
\hline $\begin{array}{l}1 \text { Situación inicial } \\
\text { (o exposición) }\end{array}$ & $\begin{array}{l}{ }^{53} \text { Y se volvieron cada uno a su casa. }{ }^{8,1} \text { Mas, Jesús se fue al Monte de los Olivos. } \\
{ }^{2} \text { Pero de madrugada se presentó otra vez en el templo y todo el pueblo acudía } \\
\text { a él. Entonces se sentó y se puso a enseñarles. }{ }^{3} \text { Los escribas y los fariseos le } \\
\text { llevan una mujer sorprendida en adulterio, la ponen en medio }{ }^{4} \text { y le dicen: } \\
\text { "Maestro, esta mujer ha sido sorprendida en flagrante adulterio" }\end{array}$ \\
\hline 2 Nudo & $\begin{array}{l}{ }^{5} \text { Moisés nos mandó en la Ley a apedrear a estas mujeres. ¿Tú qué dices?” } \\
\text { Esto lo decían para tentarle, para tener de qué acusarle. }\end{array}$ \\
\hline 3 Acción transformadora & $\begin{array}{l}\text { Pero Jesús, inclinándose, se puso a escribir con el dedo en la tierra. }{ }^{7} \text { Pero, como } \\
\text { ellos insistían en preguntarle, se incorporó y les dijo: "Aquel de vosotros que } \\
\text { esté sin pecado, que le arroje la primera piedra". }{ }^{8} \mathrm{E} \text {, inclinándose de nuevo, } \\
\text { escribía en la tierra. }\end{array}$ \\
\hline 4 Desenlace & $\begin{array}{l}{ }^{9} \text { Ellos, al oír estas palabras, se iban retirando uno tras otro, comenzando por } \\
\text { los más viejos y se quedó solo Jesús con la mujer, quien seguía en medio. }\end{array}$ \\
\hline 5 Situación final & $\begin{array}{l}{ }^{10} \text { Incorporándose Jesús le dijo: "Mujer, ¿dónde están? ¿Nadie te ha condenado?" } \\
\text { y en adelante no peques más". }\end{array}$ \\
\hline
\end{tabular}

Fuente: elaboración propia.

$4 \quad$ Cuadro elaborado por el autor. 
a) El relato describe la vuelta a sus casas por parte de quienes no comprenden a Jesús y su traslado hacia el Monte de los Olivos, en el que permanece hasta la madrugada, momento en el que se dirige al templo. La gente acude a escuchar sus enseñanzas hasta que los escribas y los fariseos llegan de modo intempestivo y le llevan a rastras a una mujer adúltera. Esta presentación (la situación inicial) da la ubicación espacio-temporal en la que se escenifica la acción.

b) Ya, frente a Jesús, los escribas y los fariseos buscan ponerlo a prueba y echa mano de la Ley de Moisés y le pregunta su opinión sobre el adulterio cometido. Esto eleva la tensión del relato (nudo) puesto que debe explayarse acerca del tema.

c) Ante el cuestionamiento, Jesús guarda silencio y escribe con el dedo en el suelo, como "desentendiéndose aparentemente del problema y dando a entender con ello que él se sitúa en un plano diferente" (Carrillo Alday, 2010, p. 267). Los escribas y los fariseos se impacientan e insisten, a lo que Jesús responde: "Aquel de vosotros que esté sin pecado, que le arroje la primera piedra" y continúa escribiendo. Esto produce un cambio de la situación inicial (acción transformadora).

d) Las palabras de Jesús hacen que los escribas y los fariseos se retiren y queda solo con la mujer. La ausencia de los acusadores suprime la tensión narrativa (desenlace).

e) Jesús se dirige a la mujer y explicita la ausencia de los acusadores y de castigo. Finalmente, Jesús expresa que él no la condena y la invita a no volver a pecar. El relato concluye con una nueva realidad (situación final).

El relato corresponde a una trama de resolución porque se sitúa en un plano pragmático en el que las actuaciones de los personajes lleva a un cambio de la realidad: los que buscaban apedrear a una pecadora y hacer caer en la trampa a Jesús no logran salirse con la suya. En contrapartida, la mujer es perdonada y Jesús enseña una nueva praxis ante el pecador.

\section{Los personajes}

En la perícopa, aparecen cuatro actores: tres principales y uno secundario, quienes tejen una trama de relaciones entre ellos y experimentan cambios a lo largo del relato.

\section{Constelación}

Las características de los personajes son presentadas con criterios de número, grados de presencia y rasgos constitutivos:

Jesús es un personaje individual y protagonista de la acción. Es un maestro que enseña y a quien los escribas y los fariseos quieren tender una trampa. Por momentos parece desinteresado, pero está atento a lo que ocurre. Su palabra es poderosa, con una respuesta es capaz de hacer que se retiren los acusadores de la mujer. Posee también una actitud de escucha y misericordia con la adúltera. 
El pueblo es un personaje colectivo que completa la escena sin una función específica en la historia. En el texto, se escucha la enseñanza de Jesús y se especifica que era una gran muchedumbre ("todo el pueblo acudía a él”).

Los escribas y los fariseos conforman un personaje colectivo y protagonista de la historia. Son dos grupos de expertos e intérpretes de ley que llevan de modo violento a una pecadora ante Jesús, con una actitud de arrogancia y deseos de tenderle una trampa. Exponen públicamente el pecado de la mujer sin mencionar al hombre que cometió adulterio con ella. Son los contrincantes de Jesús en el relato, que contraponen su dureza con la misericordia de éste. El texto da a entender que el grupo estaba formado por personas de distintas edades porque la narración dice que se retiraron comenzando por los más ancianos ${ }^{5}$.

La mujer es un personaje individual que posee un rol protagónico. Es presentada como una persona que ha pecado, pero no posee posibilidad alguna de defensa, cuya palabra no tiene importancia para los expertos de la ley. Es arrastrada a la fuerza y acusada públicamente de adulterio en el templo, lugar sagrado para los judíos y, por tanto, "se puede esperar que hayan aumentado la humillación, la vergüenza y el pánico que la mujer debió haber sentido” (O’Sullivan, 2015, p. 2). De este modo, es deshonrada y avergonzada en un contexto religioso y público. Solamente habla cuando Jesús se dirige a ella. Es víctima de la prepotencia de un grupo de hombres, quienes le recriminan su falta.

\section{Trama de relaciones de los personajes}

En el relato, las relaciones entre los protagonistas se presentan en pares.

Jesús y el pueblo componen una relación entre un personaje individual y otro grupal que se da en un contexto pedagógico: Jesús enseña y el pueblo lo escucha. Esta interacción no es de relevancia en la trama.

Los escribas y los fariseos y la mujer son personajes desproporcionados: un grupo de hombres que acusa y arrastra a una mujer. Los considerados expertos de la ley señalan a una mujer que la quebrantó y acusan a alguien cuyo testimonio no era tenido en cuenta. A primera vista podría pensarse que son antagónicos: los justos versus una pecadora, pero, con el discurrir del relato, se descubre que ambos personajes son pecadores.

Jesús, los escribas y los fariseos son una dupla antagónica. Nuevamente encontramos un personaje individual enfrentado a uno grupal. Los escribas y los fariseos le tienden una trampa a Jesús, quien no cae en ella y los obliga a retirarse, derrotados. Jesús los vence cuando hace referencia a los pecados personales. Ellos personifican el legalismo; Jesús, la misericordia. Dos praxis distintas ante el pecado ajeno, ellos no escuchan, juzgan y quieren apedrear. Por el contrario, Jesús dialoga, no juzga e invita a no pecar más. La

5 "En la Escritura, la ancianidad está relacionada con la sabiduría, la experiencia, la autoridad, la transmisión de la fe y las tradiciones", pero también "algunos ancianos de una corrupción y de una injusticia escandalosas" (Eclo 25,2; Dan 13,5) [...] "Un peligro amenaza, en efecto, a los ancianos: cerrarse a la novedad en lugar de mantenerse abiertos a la verdad; esta falsa fidelidad a la tradición (Mt 15,2-6) llevó a los ancianos a unirse a los enemigos del Cristo que lo insultaron en la cruz $(27,1.41)$. Así pues, los años no son suficientes para hacer al anciano digno del honor” (León-Dufour, 1990, p. 923). 
perícopa se enmarca en el contexto neotestamentario del conflicto entre Jesús y los escribas y los fariseos por la interpretación de la ley y la actitud con los pecadores.

Jesús y la mujer es el único caso de interacción entre dos personajes individuales en el relato. Un maestro misericordioso ante una adúltera, un sin-pecado ante una pecadora. Pese a la abismal diferencia entre ellos, se da un diálogo en el que prima la misericordia.

Esta perícopa posee una particularidad: es el único caso en el Nuevo Testamento en el que Jesús se encuentra con un pecador sorprendido in fraganti. Esto precipita una intervención de Jesús que posee un doble efecto: da una nueva enseńanza sobre el pecado personal y salva a la mujer de ser condenada a muerte.

\section{Transformaciones de los personajes}

A lo largo del relato, los protagonistas principales experimentan diferentes cambios:

Jesús comienza con una enseñanza, cuyo contenido no se encuentra en el texto. Luego defiende a una pecadora de un grupo de hombres expertos de la ley. Su misericordia hacia ella y su modo de actuar son una gran enseñanza. Primero, es reconocido como "maestro" $(8,4)$ y luego como "Señor" $(8,11)$. Pasa del silencio al diálogo, de una cierta pasividad a una acción concreta. A lo largo del relato, realiza distintos movimientos físicos que indican distintas actitudes.

Los escribas y los fariseos llegan en masa y se retiran de a uno, "comenzando por los más viejos" $(8,9)$. El grupo compacto, que trae a la mujer, se disgrega y la dejan allí sin posibilidad de aplicarle ningún castigo. Buscan vencer a Jesús mediante una trampa, pero se van derrotados. Se presentan como justos, pero se retiran conscientes de su propio pecado.

La mujer es llevada a la fuerza por los escribas y los fariseos, y se retira sola. Sus acusadores no tuvieron en cuenta sus palabras; mientras que Jesús estableció un diálogo con ella. Al inicio, se encontraba ubicada en medio de una conversación de hombres, mientras que luego habla cara a cara con Jesús. Su dignidad pisoteada es finalmente recuperada. Llega condenada y se retira perdonada.

\section{Sentimientos que despiertan}

Jesús produce empatía cuando se enfrenta a un grupo de legalistas, quienes, bravuconamente arrastran a una mujer. Se pone del lado del débil pecador y se acerca con misericordia. De este modo se produce una identificación del lector con este maestro compasivo.

Los escribas y los fariseos producen rechazo y antipatía por su uso de la fuerza y su interpretación rígida de la ley que no da lugar a la piedad ni a la comprensión. Se abusa de una mujer a quien consideran una pecadora que merece ser castigada. 
La mujer despierta cierta simpatía, es una pecadora que no tiene la posibilidad de defenderse. Es juzgada sin compasión por un grupo de hombres que la maltrata y le recrimina su pecado. Aquellos que se reconocen pecadores o que han sufrido la humillación por sus pecados, sienten gran empatía con ella, como aquellos que han experimentado en su vida la misericordia de Jesús.

Por otra parte, lectores rigoristas sentirán rechazo hacia la mujer, ya que se trata de una adúltera, como por Jesús, quien la defiende y perdona. En la antigüedad, hubo quienes se resistieron a aceptar la actitud misericordiosa del Señor: "La resistencia a admitirla se debería a que chocaba con la rigurosa praxis penitencial que se observaba en algunos sectores de la Iglesia de los primeros tiempos en el caso de adulterio" (Rivas, 2013, p. 29).

\section{Temporalidad}

El relato discurre en dos jornadas. En la primera, se relata el retorno a las casas y la ida de Jesús al Monte de los Olivos $(7,53-8,1)$ y, en la segunda, se lleva a cabo la acción principal: la discusión de Jesús con los escribas y los fariseos $(8,2-11)$. Ambos períodos transcurren de modos distintos y se ubican en el contexto de un tiempo litúrgico.

\section{Los tiempos del relato}

La perícopa posee una desproporción temporal: lo que ocurre entre la tarde/noche y la madrugada se relata en dos versículos; mientras que la discusión en el templo se describe en nueve versículos ${ }^{6}$.

El paso de la enseñanza de Jesús a la llegada de los escribas y los fariseos no posee ninguna referencia temporal, pero, por el discurrir de la acción, da la impresión de que el lapso entre ambos hechos fue breve.

\section{La velocidad del relato}

La primera parte del relato $(7,53-8,1)$ trascurre serenamente, mientras que en la segunda $(8,2-11)$, la acción se precipita de golpe y se lleva a cabo en tres bloques con dos pausas breves.

En el primer bloque (8,2-6a) los escribas y los fariseos interrumpen la enseñanza de Jesús y traen a la mujer sorprendida en adulterio y lo abordan con una pregunta. Pero Jesús, en lugar de responder, se inclina y escribe en el suelo (6b), este gesto desconcierta y crea una tensa espera ya que se produce una pausa. Tras la insistencia, en el segundo bloque (7-9a), responde de modo lapidario y logra que los escribas y los fariseos dejen el lugar, y se quedan Jesús y la mujer. Se produce otra pausa (9b), Jesús se agacha y continúa escribiendo bajo la mirada de ella. Finalmente, en el tercer bloque (10-11), Jesús se pone en pie y comienza a dialogar con la mujer.

6 En esta desproporción se puede apreciar la diferencia "entre el tiempo narrado, que es el tiempo de la historia relatada, y el tiempo narrante, que es el del relato" (Marguerat \& Bourquin, 2000, p. 141). 
En los relatos bíblicos las pausas suelen tener un fin descriptivo (Marguerat $\&$ Bourquin, 2000), pero en este caso producen tensión narrativa. El lector está en ascuas porque ve a Jesús escribir en el suelo y espera que se incorpore y actúe.

En síntesis, el relato posee dos distintas velocidades ${ }^{7}$, una rápida al inicio $(7,53-8,1)$ y una lenta luego $(8,2-11)$, con dos breves pausas que se intercalan.

\section{El tiempo religioso: la fiesta de las Chozas}

La narración transcurre en el contexto de una fiesta religiosa en la que se hace memoria de la intervención de Dios en la vida del pueblo. Los capítulos 7-9 y parte del 10 (vv. 1-18) del Evangelio de Juan están enmarcados en la fiesta de Sukkôt o de las Chozas (Tiendas, Tabernáculos o Cabañas). En sus orígenes era una celebración agrícola de la cosecha, durante la que los campesinos habitaban en chozas y reinaba la alegría. Con el devenir de los años se la asoció con la historia del pueblo y se transformó en la memoria litúrgica de la liberación de Egipto, con lo que se recuerda que Dios los hizo habitar en chozas.

En los textos más tardíos del Antiguo Testamento, la celebración de Sukkôt adquiere un sentido escatológico: lo que antes había revivido las antiguas intervenciones divinas para salvar al pueblo pasa a anunciar la futura salvación definitiva (Zac 14,16-21; ver Os 12,10).

En tiempos del Nuevo Testamento Sukkôt tenía características marcadamente mesiánicas y escatológicas. Se celebraba en el templo, y era una de las fiestas en las que los judíos debían peregrinar a Jerusalén (Dt 16,16). "La fiesta era una de las solemnidades más santas e importantes" y se caracterizaba por la alegría: “Te alegrarás durante esta fiesta... siete días estarás de fiesta..." (Dt 16,13-15). (Rivas, 2013, p. 242).

En este contexto de la celebración de la intervención salvífica de Dios en el pasado y en el futuro escatológico, Jesús se presenta salvando a una pecadora. Como Dios liberó al pueblo de la opresión egipcia, Jesús libera a esta mujer de la opresión de los expertos de la ley y cumple con las expectativas escatológicas por cuanto anuncia una salvación futura del pecador. Como Dios perdonó a su pueblo adúltero Jesús también lo hace con la mujer adúltera.

Dos elementos que no deben perderse de vista son la muchedumbre que concurría a la fiesta y el carácter alegre de la misma. La acción misericordiosa de Jesús se desarrolla delante de una multitud de peregrinos que celebra la intervención divina y que es llamada a alegrarse por ello. De este modo, el lector, tanto antiguo como actual, es invitado a vivir en un contexto religioso y con gran alegría la intervención salvífica de Jesús en favor de una pecadora.

7 "La velocidad del relato se definirá por la relación entre una duración, la de la historia medida en segundos, minutos, horas, días, meses y años, y una longitud, la del texto medido en líneas y páginas” (Marguerat \& Bourquin, 2000, p. 143). 


\section{La ubicación de la acción}

Tres lugares aparecen: las casas $(7,53)$, el Monte de los Olivos $(8,1)$ y el templo $(8,2-11)$. Los dos primeros son mencionados de modo muy escueto y desproporcionado respecto al tercero, pero permiten marcar los cambios de tiempo.

La mención a las casas no posee gran valor en sí misma, pero ayuda a contraponer el lugar al que se dirigen los fariseos que discuten con Nicodemo (en la perícopa anterior) con el lugar a donde va Jesús: el Monte de los Olivos.

Más allá de la historicidad del hecho, la mención del mismo posee un peso simbólico importante. El Monte de los Olivos era el lugar en el que Jesús se retiraba a orar al Padre. De este modo, la narración presenta que Jesús estuvo en un lugar de oración y encuentro con el Padre, antes de salir en defensa de la mujer.

El templo de Jerusalén, centro religioso y espacio del encuentro con Dios, será el escenario del enfrentamiento entre Jesús y los acusadores de la mujer y el lugar en el que ella recibirá un trato compasivo. Jesús, que venía de un lugar de oración personal, se encuentra en un lugar de oración del pueblo. Con la presencia del Señor, el templo se transforma en un lugar de perdón y misericordia se invita a la conversión y se permite hablar y escuchar a la mujer, en contraposición con la mentalidad de la época.

El recurso al Monte de los Olivos y el templo, por tanto, dan al texto un plus de simbolismo a la historia porque marcan una relación oración, encuentro con Dios y misericordia.

\section{Un contexto didáctico-legal}

En 8,2 se describe una serie de elementos que señalan un contexto de instrucción religiosa. Jesús se encuentra "otra vez en el templo", "se sentó" (posición de un maestro) y "se puso a enseñar", pero no se dice específicamente qué enseñaba. Probablemente el contenido de su enseñanza no sea relevante en el relato. Por otra parte, un lector atento se preguntaría acerca del mismo. Este interrogante produce una tensión literaria que será resuelta en el trascurrir de la trama: Jesús dará una nueva enseñanza sobre el perdón y la misericordia.

Los escribas y los fariseos son expertos y maestros de la Ley: la interpretan, aplican y enseñan. Ellos se dirigen a Jesús como "maestro", de igual a igual, y le presentan un caso real porque hacen referencia a la Ley de Moisés y le preguntan su opinión, pero con una mala intención.

La perícopa contiene varios términos legales de la Ley de Moisés, y en un contexto más amplio, los capítulos 7 y 8, contienen también un vocabulario legal (Simoens, 1997, p. 394).

No se debe perder de vista un elemento más que se añade a la trampa: la legislación romana. Los acusadores de la mujer le tienden una trampa similar como aquella acerca del pago del impuesto al César (Mt 22,15-21; Mc 12,13-17; Lc 20-26). 
Jesús es invitado a posicionarse él mismo contra Moisés, y tal vez abiertamente contra la ley romana [...] Si él no logra dar su opinión, entonces aparecerá rechazando a Moisés; si él da su veredicto, entonces aparecerá usurpando la ius gladii romana (Witherington, 1984, p. 22).

Jesús no hace referencia a la ley o la aplicación de la misma en el caso de adulterio, tampoco "dice una palabra contra la ley propiamente dicha; lo único que hace es impedir el juicio de una pecadora por hombres que a su vez son pecadores y están bajo el juicio de Dios" (Schnackenburg, 1980, p. 235). Por el contrario, da una máxima y presenta un nuevo modo de situarse ante el pecador: preguntarse por el pecado personal antes de condenar a otro. Esta será la enseñanza que practica con la mujer adúltera. El lector recibe así la respuesta a su pregunta inicial acerca del contenido.

En la perícopa anterior Nicodemo menciona la Ley $(7,51)$, pero los escribas y los fariseos no le prestan atención. Por el contrario, echarán mano de ella al presentar el caso de la adúltera a Jesús.

En el relato parecen dos visiones legales contrapuestas. Por un lado, la de los escribas y fariseos que interpretan de modo literal, cerrado y sin misericordia. Por el otro, Jesús hace una nueva interpretación más amplia y misericordiosa, que mira la salvación y no el pecado. Así el texto presenta dos praxis contrapuestas que interpelan al lector y lo invitan a tomar una posición.

\section{Movimientos y gestos}

La perícopa posee un gran dinamismo puesto que contiene varios desplazamientos y movimientos corporales que dan un mensaje en sí mismos.

Jesús llega al templo y se sienta a enseñar. Es de suponer que se pone de pie para escuchar a los escribas y a los fariseos, mientras la mujer está en medio de ellos. Luego, él se agacha y escribe con el dedo ${ }^{8}$, vuelve a pararse y responde, nuevamente se agacha y escribe. Cuando el grupo de los expertos de la Ley se retira, nuevamente se pone de pie y habla con la mujer. Cada una de sus posiciones implica una actitud o acción:

- Sentado: enseña como maestro.

- Parado: habla y escucha a los pecadores, o sea, todos los protagonistas de la escena. Se dirige a ellos cara a cara, sin sentirse superior e invita a un cambio de vida.

- Agachado: se inclina ante el pecador antes y después de invitarlo a reconocerse como tal. En esta posición escribe.

8 "El contexto más bien parece exigir que, al igual que la Ley que se entregó a Moisés fue escrita por el dedo de Dios en la piedra, ahora Jesús escriba la suya en la tierra; es una Ley que tiene en cuenta la debilidad del hombre; al hombre se le da la posibilidad de borrar su pasado; es una ley para el hombre, que es terreno, frágil. Jesús, agachado sobre la tierra en la que escribe, es toda una expresión; inclinado sobre el hombre, venido no a condenar al mundo, sino a salvarlo. Jesús agachado sobre la tierra y la mujer en pie. Algo similar acontece en el lavatorio de los pies. Dios se abaja, para que el hombre sea ensalzado" (Castro Sánchez, 2001, pp.188-189). 
Jesús es el único que permanece en el lugar durante toda la escena y quien realiza más movimientos corporales.

Los escribas y los fariseos llegan con una mujer que arrastran y empujan al medio, parados, miran a Jesús y luego de escuchar su respuesta se retiran uno por uno. Se dispersan y ya no empujan a nadie, luego de la respuesta de Jesús. Su fuerza era sentirse justos, pero, al quedar expuestos como pecadores, huyen y se van con su pecado.

La mujer es violentamente llevada a la fuerza contra su voluntad, es ubicada entre los escribas y los fariseos y Jesús; luego de la respuesta de Jesús, queda sola con él y se va por su cuenta, perdonada y salvada.

La secuencia de sus movimientos corporales: parado-agachado-parado-agachado-parado, muestra una discusión por una mujer entre un maestro y un grupo. El maestro parece no prestar atención al agacharse a escribir, pero, al ponerse en pie, dice algo que produce la disgregación del grupo que trajo la mujer. Ya solos, el maestro y la mujer, éste dialoga con ella, quien finalmente se retira.

La secuencia de desplazamientos y movimientos físicos analizada sin los diálogos (a modo de cine mudo), ayuda a apreciar mejor su profundidad. Un espectador que sólo viera los hechos y desconoce los diálogos o la temática de la escena, descubriría la fuerza de los gestos y cómo se desarrolla la acción.

\section{Los diálogos}

La perícopa posee dos diálogos simples con características distintas.

El primero: la consulta sobre una situación y la respuesta a la misma. Los interlocutores son Jesús y los escribas y fariseos. Entre ellos encontramos a la mujer sobre quien versa la conversación, pero no se le permite intervenir. Los interlocutores, todos varones, hablan con ella en el medio, de algún modo la discusión acerca de ella la atraviesa, sin que ella pueda proferir palabras.

Los escribas y los fariseos se dirigen a Jesús como maestro y le exponen el pecado de la mujer, recurren a la mayor autoridad del judaísmo: Moisés y su Ley; así, justifican el castigo. No se basan en una costumbre o tradición oral, sino en el texto escrito de la Torá.

Con la pregunta: “¿Tú qué dices?”, buscan enfrentar a Jesús con Moisés y poder acusarlo. Un modo solapado de ponerlo entre la espada y la pared. Jesús no responde y guarda silencio, lo que ya es una respuesta y, por tanto, parte del diálogo. Sólo ante la insistencia habla.

Con gran inteligencia no cae en su trampa e incluso casi con ironía "jJesús lanza una orden de ejecución!: "Quien no tenga pecado, que le tire la primera piedra». Pero no hay ejecución” (Tunc, 1999, p. 56). Esta situación confirma que un pecador no puede condenar o castigar a otro pecador, se corre el eje de la discusión a otro campo: la experiencia personal de pecado. 
La respuesta de Jesús trae un juego de sentido: no niega que el pecador deba ser castigado, sino que sólo quien "esté sin pecado" puede castigarlo. Ambos sujetos hablan del pecado y el castigo, pero de modos distintos. Con gran sutiliza, Jesús pregunta a los escribas y a los fariseos si ellos no son pecadores.

El segundo diálogo está compuesto por una pregunta, su respuesta y una invitación. Los interlocutores son dos: Jesús y la mujer, un varón y una mujer. Pero, a diferencia del diálogo anterior, aquí la mujer toma parte del mismo porque habla cara a cara con Jesús. Han desaparecido los acusadores.

Jesús, luego de un silencio, toma la iniciativa y comienza el diálogo con la mujer, a quien los escribas y los fariseos no le permitieron hablar. Comienza preguntándole por "ellos" (sus acusadores), y luego hace una pregunta retórica, puesto que ambos están solos: “¿Nadie te ha condenado?”, lo que hace que la mujer confirme lo obvio: nadie la acusa. Es de resaltar que no hay pregunta por su pecado, sino por los acusadores.

Por su parte, ella da un paso más y lo reconoce como "Señor" y logra ver algo que los escribas y los fariseos no vieron: la divinidad de Jesús. Ella no está dialogando con un maestro, sino con Dios.

Finalmente, Jesús afirma que Él tampoco condena y la invita a un cambio de vida.

En el texto no hay diálogo de los escribas y los fariseos con la mujer, lo que deja en claro su postura de superioridad y se contrapone narrativamente al obrar de Jesús.

\section{Pausa y preguntas retóricas}

Cuando los escribas y los fariseos se van, se produce una pausa en el relato. Sólo permanecen en escena Jesús y la mujer. El relato no describe los pensamientos ni los sentimientos de la pecadora.

Ella no habló hasta que Jesús le dirigió la palabra. Estaba ante un rabí, un maestro, un hombre al que otros escuchaban, que tenía autoridad y tan poderoso que hizo que escribas y fariseos se retiraran. Pero este hombre era distinto, su poder no era como el de los maestros de Israel. Él se dirigió a ella, le habló e hizo una pregunta, para comenzar un diálogo, una conversación.

Jesús hace dos preguntas retóricas: "Mujer, ¿¿ónde están [tus acusadores]? ¿Nadie te ha condenado?" $(8,10)$. Ambas son obvias, ya se habían retirado los escribas y los fariseos. Pero la segunda posee un dato más, ya que Jesús se incluye, él tampoco la condena, ni lo hará.

Al final, no le dice explícitamente que la perdona, sino que tampoco la condena. Él vino para salvar, no para condenar. No sólo le da a la mujer una segunda oportunidad, también la hace responsable de su propio futuro. Ella ya no es más un objeto, llevada y traída por otros, sino un sujeto libre y responsable ante Dios. (Conti, 2002. p. 104).

El texto se enfrenta a una mentalidad machista, implacable ante el engańo y el adulterio cometido por las mujeres casadas con una mentalidad igualitaria, que mira a la mujer como una persona de igual condición y dignidad que el hombre. Jesús escucha a los pobres, los excluidos y los sin voz de la sociedad. 


\section{Pecadores, anamartetos, misericordia}

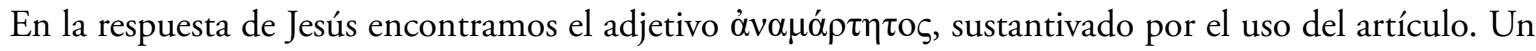
hápax de la Escritura, lo que no permite una comparación intrabíblica, pero cuyo significado está atestiguado en la literatura griega como una persona que no se equivoca, sin error, sin pecado, preservado de error, sin falla. (Pabón, 2014; Günther, 1993).

Las palabras de Jesús derriban los argumentos de condena de los escribas y los fariseos y desintegran el grupo. Jesús apela a la experiencia personal de cada uno de sus oyentes: todos son pecadores y, por tanto, nadie puede castigar a su prójimo. Aquellos que se consideraban justos no soportan estar ante una mujer pecadora como ellos; ni ante Jesús, el verdadero anamartetos. Por el contrario, la mujer adúltera se queda ante Jesús, permanece, no se marcha y, por tanto, obtiene misericordia.

Jesús es presentado como un anamartetos misericordioso. Él conoce el pecado de la mujer, pero no la juzga; es delicado en sus palabras y modos de hablar. No condena, pero invita a no volver a pecar. Por otra parte, "Jesús tampoco los condena a ellos [los escribas y los fariseos], al mismo tiempo que les hace tomar conciencia de su pecado" (Leon-Dufour, 1992, p. 253). El grupo acusador no reconoce sus pecados, su orgullo herido no les permite aceptar el perdón, por tanto, prefieren marcharse. Las palabras de Jesús hacen que su propia conciencia los condene.

El texto propone distintas actitudes ante el pecado personal y del hermano. Ante el pecado propio, se puede actuar como los escribas y los fariseos, que se consideran justos e incapaces de reconocer su pecado, o, como la mujer, quien reconoce su falta y es perdonada. Ante el pecado ajeno, se puede proceder como los escribas y los fariseos, quienes juzgan de modo implacable o, como Jesús, quien escucha, perdona e invita al cambio de vida.

En el relato la mujer queda ubicada entre la condena y la misericordia. La primera, la arrastra sin piedad y no le permite hablar; por el contrario, la misericordia dialoga con ella y le permite caminar sola.

Los escribas y los fariseos se dirigen a Jesús como "maestro" $(8,4)$, mientras que la mujer los llamará "Señor" $(8,11)$. Irónicamente, una pecadora reconoce al Kyrios, mientras que los escribas y los fariseos sólo ven un rabi. Los que se consideraban justos se van avergonzados en su pecado y, sin encontrarse profundamente con el misericordiae vultus; la pecadora se va perdonada y reconoce el señorío de Jesús.

\section{Análisis narratológico del contexto}

La perícopa estudiada, pese a ser considerada una interpolación, posee sentido en sí misma y podría estar ubicada en otro lugar con o sin relación con su contexto, como ocurre en algunos manuscritos antiguos. Sin embargo, ante su ubicación actual surge la pregunta acerca de por qué se encuentra allí.

Schnakenburg expone que quien hizo la inserción tenía una razón, un objetivo por así decirlo y presenta una posible explicación de ello, pero concluye que las conexiones con las perícopas inmediatas están basadas en "puntos de vista externos". 
¿Cómo se llegó a que la perícopa de la adúltera acabase entrando en ese lugar del cuarto Evangelio, al menos según la mayor parte de los manuscritos? En tiempos pasados se creyó a veces que se trataba de un entreacto indispensable entre las escenas del cap. 7 y del cap. 8; opinión insostenible y que hoy se rechaza. Pero el hombre a quien debemos esta inserción, no lo hizo sin reflexionar.

De primeras, cabe referirse a estos puntos externos de enlace: a) De la enseñanza de Jesús en el templo se habla en 7,14.28; 8,20; cf. 8,2. b) En 7,20 y 8,15a Jesús advierte contra un juicio

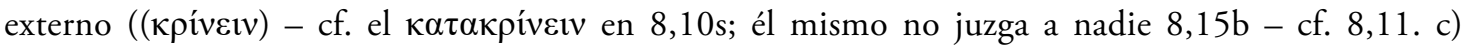
Repetidas veces se alega la autoridad de la ley: 7,19.23.25; 8,18; Nicodemo habla del "juicio de la ley" (7,51); cf. 8,5. d) Los fariseos comparecen como enemigos de Jesús en 7,48 y 8,13; cf 8,3. Incluso por lo que hace a la situación en que Jesús se halla, pueden establecerse ciertas semejanzas: el pueblo simpatiza con él, y al menos (en el cap. 7) algunos grupos, mientras que los círculos dirigentes se le enfrentan con escepticismo y animosidad. El propósito homicida de los enemigos $(7,1)$ encaja en el marco general de estos capítulos joánicos, y con él concuerda el objetivo de los escribas y fariseos en 8,6a. Juan 7 está montado sobre discusiones (en este aspecto hay que insertar también los vv. 15-24) y ahí se intercala la cuestión propuesta a Jesús en 8,5. En los diálogos joánicos Jesús se muestra como superior y capaz de poner en aprieto a sus oyentes; no es otro su comportamiento en esta historia de la adúltera. Pero los contactos de la perícopa con las secciones joánicas inmediatas no van más allá de los aspectos externos. Y han sido precisamente estos puntos de vista externos los que han guiado a los interpoladores posteriores. La inserción debía realizarse provocando la menor sorpresa y dificultad. Mas para el cuarto Evangelio representa un cuerpo extraño, que incluso estorba y rompe la conexión de los capítulos 7 y 8 (Schnakenburg, 1980, pp. 235-236).

El acercamiento al texto desde el método histórico-crítico señala que la perícopa pertenece a otra tradición distinta al resto del Evangelio. Pero una mirada desde la narrativa, no tan preocupada por la historia de los elementos que conforman y su proceso de escritura, sino por el texto final que transmitió la comunidad, se preguntaría sobre el efecto de sentido que quiso producir el autor cuando introdujo esta perícopa allí.

En este punto, pueden ayudar a comprender esto algunas técnicas utilizadas en el cine. Cuando un director interrumpe el curso de una escena con un déjà vu y rápidamente se vuelve a la escena principal, se produce una conexión entre pasado y presente que da un nuevo sentido a la historia.

Probablemente es lo que ha sucedido con este texto en el cuarto Evangelio. En alguna instancia del proceso de transmisión del texto se introdujo esta perícopa, no exenta de tensiones, para dar un sentido nuevo al relato. Esto en narratología se denomina "una secuencia sándwich" o "engaste":

Esta penetración mutua de episodios no es más que una astucia de dramaturgo. La construcción por engaste provoca un fenómeno de eco entre la escena engastada y la escena que engasta, y dicho eco produce una ganancia de sentido; las dos escenas se interpretan una por la otra y una gracias a la otra (Marguerat $\&$ Bourquin, 2000, p. 66).

Llama la atención que algunos autores señalan la relación con la perícopa posterior $(8,12-20)$, pero no con la anterior $(7,40-52)$. La hipótesis de este estudio sostiene que el texto guarda relación con ambas perícopas. 
En la perícopa anterior $(7,40-52)$ se suscita una discusión acerca de la identidad de Jesús como Mesías. Al final de la misma, ante los sacerdotes y los fariseos, Nicodemo pregunta: “¿Acaso nuestra Ley juzga a un hombre sin haberle antes oído y sin saber lo que hace?” $(7,51)$ allí se hace referencia al texto Dt 1,16: "Y di entonces esta orden a vuestros jueces: «Escuchad lo que haya entre vuestros hermanos y administrad justicia entre un hombre y su hermano o un forastero"”. Tanto en el Texto Masorético como en la Septuaginta, la prescripción versa siempre sobre varones: hermanos, hombre, hermano y forastero.

En el Evangelio Nicodemo utiliza un término más general: òv $\theta \rho \omega \pi \circ \varsigma$ : ser humano, persona y, en un segundo sentido, varón o esposo e, incluso, hijo o esclavo (Sand, 2005, pp. 298-310). El uso de este término permite una interpretación más amplia e inclusiva de la ley: se debe escuchar a todo ser humano, sin importar si es varón o mujer.

En un contexto cultico y didáctico, los escribas y los fariseos traen una mujer adúltera sobre quien ya habían tomado una decisión, es decir, la condenaron sin escucharla, puesto que su testimonio no era válido, según su interpretación Dt 17,6. Por el contrario, cuando Jesús queda a solas con la mujer la escucha antes de tomar cualquier decisión.

Aquello que había insinuado Nicodemo cuando dijo que primero se debía escuchar a la persona antes de juzgarla, como decía la Ley, se concretiza en Jesús, quien dialoga con la mujer. Jesús no sólo cumple la Ley, sino que extiende su alcance. Por el contrario, los escribas y los fariseos poseen una interpretación más estrecha y reductiva de la Ley, puesto que no desean ni siquiera escuchar a un varón.

En cuanto a la perícopa posterior, algunos autores (Vawter, 1977; Perkins, 2004) confirman la relación de la misma con el texto de la mujer adúltera. Rivas expone en su comentario:

Esta perícopa ha sido incluida dentro del evangelio de Juan, en un bloque en el que Jesús afirma que Él no juzga a nadie $(8,15)$, inmediatamente antes de que se revele como Luz del mundo $(8,12)$. El responsable de la interpolación habrá considerado que este es el lugar apropiado para conservar este texto en el que los fariseos y los escribas juzgan como intérpretes de una Ley tenida por ellos como "luz del mundo". La perícopa muestra que el juicio de los escribas y los fariseos es erróneo, y estos quedan descalificados. Se abre un espacio para que Jesús se revele como "Luz del mundo" (Rivas, 2013, p. 265).

La interpolación del 7,53-8,11, en la opinión de este estudio, por un lado, permite ver cómo lo insinuado por Nicodemo se cumple en Jesús, quien hace nueva lectura de la Ley de Moisés. Ya no solamente los varones, sino también las mujeres y todos aquellos que son excluidos y no tenidos en cuenta por la sociedad. La praxis de Jesús extiende el alcance de la Ley mosaica porque todo ser humano, sin importar su raza, sexo o condición, debe ser escuchado y tratado con misericordia.

Por otro, el lector que vio el actuar misericordioso y compasivo de Jesús logra comprender sus palabras de un modo más profundo. Él es la "luz del mundo" $(8,13)$ que vence las tinieblas del pecado y de la muerte. La misericordia practicada por Jesús muestra la validez de su testimonio válido y la verdad de su juicio. 


\section{Conclusión}

Este texto posee una gran riqueza en humanidad y compasión. Presenta dos actitudes contrapuestas ante el pecado ajeno: la de los escribas y los fariseos, y la de Jesús e invita a hacer una opción entre éstas. Dos praxis diferentes se enfrentan en un magistral duelo: legalismo y misericordia, dureza y comprensión. Jesús se presenta misericordioso y solidario con el pecador, lo escucha, perdona y evita los juicos implacables porque llama a la conversión.

El modo de relacionarse Jesús con la mujer es novedoso y revolucionario. En una sociedad de posición misógina y machista en la que la palabra de las mujeres no tenía valor, él las escucha y dialoga con ellas. Cuestiona así el statu quo acerca de quiénes podían dar testimonio y quiénes no. De este modo, presenta una nueva interpretación de la Ley, en la que hombres y mujeres tienen la misma dignidad ante Dios. Una nueva praxis que los seguidores de Jesús, como ejemplo de su maestro, deberán practicar: escuchar a la mujer, dialogar con ella, hablar de igual a igual.

El análisis de la estructura del texto permitió inferir que la pregunta sobre el pecado personal, hecha por Jesús, está ubicada no sólo en el centro de la discusión, sino que ella es el corazón del enfrentamiento.

La aplicación del método narrativo puso de manifiesto una cantidad de elementos y detalles del texto (el discurrir de la trama, los personajes, los sentimientos que se suscitan, etc.), que podrían ser pasados por alto por otros métodos o aproximaciones. Pensamos que ambos análisis son un aporte al estudio de la perícopa por los datos y aspectos que arroja.

El relato leído en su contexto narrativo muestra a Jesús como quien escucha a todos, hombres y mujeres, antes de juzgar. Así se amplía el alcance de la Ley, como las palabras de Nicodemo lo habían sugerido. Y, tras contemplar el actuar misericordioso de Jesús, se da una comprensión más profunda del título "luz del mundo" y su presentación como aquel cuyo testimonio y juicio son verdaderos.

Por otra parte, aunque el análisis contextual de la perícopa ofrece una respuesta posible y válida a la cuestión de la ubicación actual, esta presentación es un first approach al problema. La temática debe ser profundizada en estudios e investigaciones posteriores que tengan en cuenta el contexto de toda la obra, como también otros aspectos señalados por los especialistas. 


\section{Referencias}

Brown, R. (1999). El Evangelio según Juan. I-XII. Introducción, traducción y notas. Madrid: Ediciones Cristiandad.

Carrillo Alday, S- (2010). El Evangelio según San Juan. El Evangelio del Camino, de la Verdad y de la Vida. Estella: Verbo Divino.

Castro Sánchez, S. (2001). Evangelio de Juan. Comprensión exegético-existencial, Sevilla: Desclée De Brouwer.

Conti, C. (2002). "El misterio del texto elusivo: Juan 7,53-8,11. Revista de interpretación biblica latinoamericana 41 (1) 93-106.

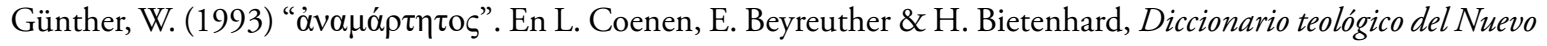
Testamento. (Vol. III, 319). Salamanca: Sígueme.

Kasper, W. (2014). La misericordia. Clave del evangelio y de la vida cristiana. Santander: Sal Terrae.

Krüger, R., Croatto, S. \& Míguez, N. (1996). Métodos exegéticos. Buenos Aires: Publicaciones Educab.

León-Dufour, X. (I990). Vocabulario de teología biblica. Barcelona: Herder.

León-Dufour, X. (1992). Lectura del Evangelio de Juan. Jn 5-12. (Vol. II). Salamanca: Sígueme.

Marguerat, D. \& Bourquin, Y. (2000). Cómo leer los relatos bíblicos. Iniciación al análisis narrativo. Santander: Sal Terrae.

O’Sullivan, M. (2015). “Reading John 7:53-8:11 as a narrative against male violence against women”. HTS Teologiese Studies 71 (1) 1-8. Recuperado de http://dx.doi.org/10.4102/hts.v71i1.2939.

Pabón, J. M. (2014). Diccionario manual griego-español, Barcelona: Larousse.

Perkins, P. (2004). “Evangelio de Juan”. En R. Brown; J. Fitzmeyer \& R. Murphy (Eds.), Nuevo comentario biblico San Jerónimo. Nuevo Testamento y artículos temáticos (524-589). Estella: Verbo Divino.

Rivas, L. H. (2013). El Evangelio de Juan. Introducción. Teología. Comentario. Buenos Aires: San Benito.

Sánchez Castelblanco, W. G. (2010). “Jesús y la mujer adúltera. Análisis exegético-teológico de Jn 7,53-8,11”. Franciscanum, LII (154), 17-52.

Sand, A. “òv $\theta \rho \omega \pi \mathrm{o}{ }^{\prime}$ (2005). En H. Blaz \& G. Schneider. Diccionario exegético del Nuevo Testamento (298-310). Salamanca: Sígueme.

Schnackenburg, R (1980). El Evangelio según San Juan. Versión y comentarios. (Vol. II). Barcelona: Herder.

Simeons, Y. (1997). Secondo Giovanni. Una traduzione e un'interpretazione. Bologna; Edizioni Dehoniane.

Tunc, S. (1999). También las mujeres seguian a Jesús. Santander: Sal Terrae.

Vawter, B. (1972). “Evangelio según San Juan”. En R. Brown; J. Fitzmeyer \& R. Murphy (Eds.), Comentario biblico San Jerónimo (399-529). Madrid: Ediciones Cristiandad.

Witherington, B. (1984). Women in the ministry of Jesus: a study of Jesus' attitudes to women and their roles as reflected in His earthly life. Cambridge, New York, Melbourne: Cambridge University Press. 